\title{
Erratum to: A Speech Generating Device for Persons with Intellectual and Sensory-Motor Disabilities
}

\author{
Giulio E. Lancioni ${ }^{1} \cdot$ Nirbhay N. Singh $^{2}$ • \\ Mark F. O'Reilly ${ }^{3}$ - Vanessa A. Green ${ }^{4}$. \\ Larah Van der Meer ${ }^{4}$. Gloria Alberti ${ }^{5}$. \\ Viviana Perilli $^{5}$ - Adele Boccasini ${ }^{5}$. \\ Maria L. La Martire ${ }^{5}$. Russell Lang ${ }^{6}$
}

Published online: 28 January 2016

(C) Springer Science+Business Media New York 2016

\section{Erratum to: J Dev Phys Disabil \\ DOI 10.1007/s10882-015-9424-6}

In the original published version of this article, information pertaining to ethical approval, informed consent, and potential conflicts of interest was only partially noted. The authors have included this information below. This error has no implications for the reported results.

The online version of the original article can be found at http://dx.doi.org/10.1007/s10882-015-9424-6.

Giulio E. Lancioni

giulio.lancioni@uniba.it

Nirbhay N. Singh

nirbsingh52@aol.com

Mark F. O'Reilly

markoreilly@austin.utexas.edu

Vanessa A. Green

Vanessa.Green@vuw.ac.nz

Larah Van der Meer

Larah.vanderMeer@vuw.ac.nz

Gloria Alberti

glorya84@hotmail.com

Viviana Perilli

vivianaperilli@gmail.com

Adele Boccasini

adele.boccasini@alice.it 


\section{Ethical Approval}

The Scientific and Ethics committee of the Lega F. D'Oro, Osimo, Italy provided approval for the study. All procedures used during the study were in accordance with the ethical standards of the institutional and/or national research committee and with the 1964 Helsinki declaration and its later amendments or comparable ethical standards.

\section{Informed Consent}

All three participants were apparently interested in using a technology device as the one evaluated in the study, and thus in being involved in the study. Their legal representatives, moreover, had provided a formal consent for their participation in the study.

\section{Conflict of Interest}

The authors report no conflicts of interest. The authors alone are responsible for the content and writing of this article.

Maria L. La Martire

marialuisa.lamartire@virgilio.it

Russell Lang

r130@txstate.edu

1 Department of Neuroscience and Sense Organs, University of Bari, Corso Italia 23, 70121 Bari, Italy

2 Medical College of Georgia, Georgia Regents University, Augusta, GA, USA

3 University of Texas at Austin, Austin, TX, USA

4 Victoria University of Wellington, Wellington, New Zealand

5 Lega F. D'Oro Research Center, Osimo, Italy

6 Texas State University, San Marcos, TX, USA 